\title{
AC 2007-1695: ENGINEERING ENTERPRISE ALLIANCE: A K-12, UNIVERSITY AND INDUSTRY INITIATIVE TO CREATE A PATHWAY TO ENGINEERING AND SCIENCE CAREERS
}

\section{Douglas Oppliger, Michigan Technological University}

Mr. Oppliger is a professional engineer and a lecturer in the Engineering Fundamentals department at Michigan Technological University. He actively works with students and teachers to get more engineering content into K-12 education. His outreach includes advising a FIRST robotics team and assisting several local FIRST LEGO League teams. In 2004 Mr. Oppliger was awarded the Distinguished Faculty Award for Service largely because of this outreach work. He is currently working with the Utica Public School System in suburban Detroit to develop a pre-college engineering technology course that will be a model for the state. He has presented papers on engineering education at many ASEE and FIE conferences. Before coming to Michigan Tech, Mr. Oppliger taught math and science at the secondary level for 11 years. Before that, he worked for 5 years as a project engineer in the marine construction industry.

\section{Shawn Oppliger, Copper Country Intermediate School District}

Ms. Shawn Oppliger (M.S.) is director of the Western Upper Peninsula Center for Science, Mathematics, and Environmental Education and science and mathematics consultant at Copper Country Intermediate School District. The Western UP Center is member of the Michigan Math and Science Centers Network. Shawn has secondary teacher certification in biology, math, physics and chemistry and a Masters of Science from Michigan Technological University (MTU). She taught math and science for thirteen years at the high school level, before taking the position as the director of the Western UP Center. In her current position, she develops and implements programming for students and teachers, provides educational leadership and curriculum support for school districts in Baraga, Houghton, Keweenaw, Gogebic and Ontonagon counties of Michigan. The Western UP Center has received awards from Michigan Association of School Boards and Lake Superior Binational Forum for excellent educational programming. Shawn was recognized for outstanding service to education community by MTU in 2005 through induction into Academy of Educators.

\section{Mary Raber, Michigan Technological University}

Ms. Mary Raber is the director of the Enterprise Program at MTU. In this role, she secures funding and projects from external sources, oversees day-to-day operation of the program and teaches various instructional modules in the curriculum. Prior to Michigan Tech, Ms. Raber worked in the automotive industry for 14 years, holding various positions in engineering and management. Mary holds a B.S.M.E from the University of Michigan and an M.B.A. from Wayne State University.

\section{Robert Warrington, Michigan Technological University}

Dr. Warrington is currently Dean of Engineering at Michigan Technological University and Director for the Institute for Interdisciplinary Studies. Dr. Warrington was the founder and Director of the Institute for Micromanufacturing at Louisiana Tech University. Dr. Warrington served in the US Army for two years and on the faculty at Montana State University for eight years, was the head of the Mechanical and Industrial Engineering Department at Louisiana Tech University for 11 years, and was the Director of the Institute for Micromanufacturing from 1991-1996. Dr. Warrington serves on the Council on Engineering Education, was Chairman of the Advanced Energy Systems Division, is a member of the Board on International Standards for ASME, and is a member of the Committee on Accreditation for ABET. He was an associate editor for the ASME/IEEE Journal of Microelectromechanical Systems (he is currently editor emeritus) and has over 140 technical publications and presentations (18 invited) and 37 research grants from foundations, government and industry. Dr. Warrington's research interests include 
microengineering (particularly micro heat transfer and fluid flow), micromanufacturing, and micromechanical machining processes. 


\title{
Engineering Enterprise Alliance \\ A K-12, University and Industry Initiative to Create a Pathway to \\ Engineering and Science Careers
}

\begin{abstract}
Since the fall of 2000, Michigan Technological University's undergraduate Enterprise Program (www.enterprise.mtu.edu) of cross-disciplinary problem solving and product generation has created active learning environments for undergraduate students across campus. Teams of students from a variety of disciplines are given an opportunity to work in a business-like setting to solve real-world engineering problems supplied by industry. Through participation in the program, Enterprise students are able to develop technical competence as well as an understanding of the practical application of skills and knowledge in areas such as communication, business, leadership, teamwork, global competition, and entrepreneurship.
\end{abstract}

Michigan Tech strongly believes that in order to increase the number of students who select to enroll in technical programs, students must be introduced to engineering and science while they are in elementary and secondary school. The hands-on educational model of the Enterprise Program has been very successful in generating an excitement about engineering and science at the undergraduate level, so expanding this model to the K-12 system would seem to be a natural progression.

Michigan Tech is in the process of working with high school teachers in local school districts to create an Enterprise-like model that builds upon the success of the undergraduate program, yet is tailored for the secondary learning environment. A joint team of MTU and high school faculty and administrators have been working together to develop a precollege-enterprise experience designed to introduce and involve students in engineering and technology. Project based, contextual learning experiences will be the foundation of the program, and are intended to increase the technological awareness of the future workforce. Our goal is to develop and implement a model at the regional level that can be readily transferred to the state and national levels.

This paper will summarize the process used at Michigan Tech to develop a pre-college enterprise program structure, the model to be piloted in fall 2007, and associated challenges encountered such as driving change in the high school curriculum, development of a support structure and proposed mechanisms to sustain the program beyond the pilot year.

\section{Background}

In 2004, Michigan's Lt. Governor's Commission on Higher Education and Economic Growth ("Cherry Commission") was tasked by Michigan Governor Jennifer Granholm to formulate policy recommendations to achieve three goals: 
1. Double the percentage of Michigan residents attaining post secondary degrees in ten years.

2. Better align Higher Education in Michigan with emerging employment areas in the state's economy.

3. Build a workforce equipped for success in the twenty-first century

The commission was organized and met in various locales to perform its work. Subgroups were organized to facilitate more intensive investigation into four main areas including improving preparation, expanding participation, increasing degree completion, and maximizing economic benefits. After extensive research, public forums and collaboration with business leaders and educators, the final recommendations were presented in three main categories; Raise the Bar, Clear the Path and Win the Race.

Just before the Cherry Commission was organized, Dennis Harbor, Superintendent of the Copper Country Intermediate School District and Glenn Mroz, President of Michigan Technological University, met to discuss efforts to increase linkages between local K-12 education and the University. Their goal was to entice and excite students to attend Michigan Tech. As discussions evolved and the work of the Cherry Commission became known, the K12 partnership initiative evolved to answer the call of the commission. A small group of professionals from Michigan Tech, the Michigan Tech Enterprise Smart Zone and the Copper Country Intermediate School District met with area superintendents in early 2005 and received their formal charge to provide structure to implement the recommendations of the Cherry Commission.

This group is now called the Mroz Commission and has focused on three main areas: help strengthen curricula in high schools to prepare more students for higher education, increase enrollment and retention at the undergraduate level, and extend into the K-12 system the excitement created by the Michigan Tech Enterprise Program through active, discovery-based learning. The goal is to create a culture of entrepreneurship, and to foster these outcomes by strengthening the partnerships between higher education, local schools and the business smart zone. We feel that these collaborative efforts can become a model for the state and for the nation as we strive to address the goals identified by the Cherry Commission. One particularly exciting, and innovative way to achieve the objectives of the Mroz Commission is the integration of Michigan Tech's innovative Enterprise Program into the K-12 environment. Michigan Tech's Enterprise Program is unique in the nation and is recognized as one of the definitive approaches for entrepreneurship education at the undergraduate level.

Since the fall of 2000, Michigan Tech's Enterprise Program concept of cross-disciplinary problem solving and product generation has created active learning environments for undergraduate students across campus. Within the program, teams of students from a broad base of disciplines are provided an opportunity to work for several years in a business-like setting to solve real-world problems supplied by industry, or of their own creation. Through participation in the program, Enterprise students are able to develop not only technical competence, but also an understanding of the practical application of skills and knowledge in areas such as communication, teamwork, leadership, global markets and competition, environmental and societal issues, ethics and business. 
Michigan Tech strongly believes that in order to increase the number of students who select to enroll in college level engineering and science programs they must be introduced to these compelling areas at the elementary and secondary levels. By combining education of these topics with the experiential learning model of the Enterprise Program, we believe we can help to generate a greater interest in engineering and science careers, as well as to spark the possibilities of new product and business generation among the participating high school students.

As can be seen in the following chart (Figure 1), enrollment in Michigan Tech Enterprise Program has been steadily growing as word of this exciting learning environment spreads. Even more exciting are the improvements we see in retention (Figure 2). By engaging students in this experiential learning environment, we see a significant difference in a student's decision to stay within the STEM fields of study. In addition, surveys of incoming freshmen are showing that the opportunity to participate in Michigan Tech's Enterprise Program is influencing their decision on choice of college. Our hope is that by embedding an Enterprise-like curriculum into the high schools, we will see similar results in enrollment and retention in the STEM fields of study at the high school level.

Figure 1 - Enterprise Program Enrollment History

\begin{tabular}{|l|l|l||l|l|l|l|}
\hline Class/Year & 00-01 & $\mathbf{0 1 - 0 2}$ & $\mathbf{0 2 - 0 3}$ & $\mathbf{0 3 - 0 4}$ & $\mathbf{0 4 - 0 5}$ & $\mathbf{0 5 - 0 6}$ \\
\hline Sophomore & 85 & 140 & 150 & 160 & 194 & 143 \\
\hline Junior & 60 & 85 & 110 & 150 & 204 & 231 \\
\hline Senior & 85 & 86 & 140 & 150 & 157 & 219 \\
\hline Total & 230 & 311 & 405 & 460 & 555 & 604 \\
\hline $\begin{array}{l}\# \\
\text { Enterprises }\end{array}$ & 11 & 15 & 17 & 18 & 22 & 24 \\
\hline
\end{tabular}

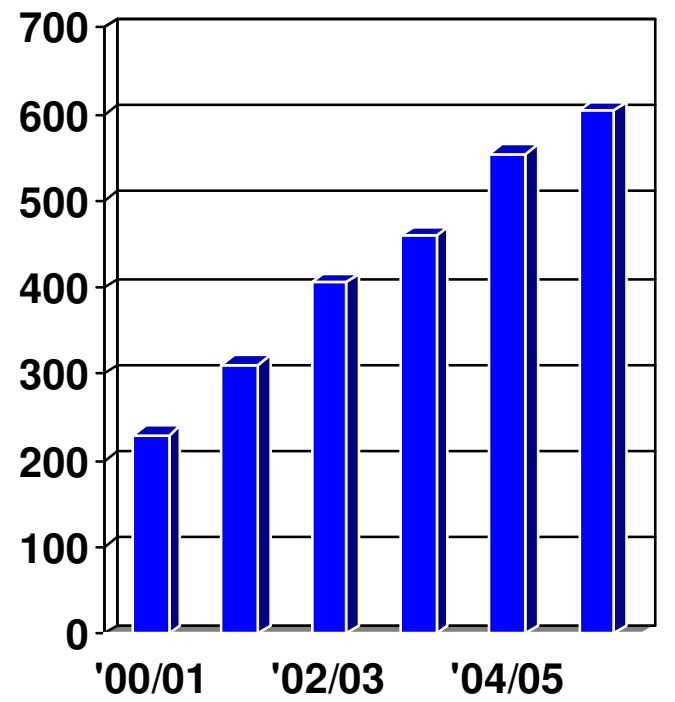

Figure 2 - Enterprise Program Retention Rates

\begin{tabular}{|l|l|l|l|}
\hline Category & Enterprise & $\begin{array}{l}\text { Non- } \\
\text { Enterprise }\end{array}$ & Notes \\
\hline $\begin{array}{l}\text { Third Year Retention - Engineering } \\
\text { - Fall 2001 FTIACs }\end{array}$ & $\begin{array}{l}93.2 \% \\
(\mathrm{n}=103)\end{array}$ & $\begin{array}{l}67.2 \% \\
(\mathrm{n}=691)\end{array}$ & $\begin{array}{l}\mathrm{p}<0.0001 \\
\text { (highly } \\
\text { significant) }\end{array}$ \\
\hline $\begin{array}{l}\text { Second Year Retention - Technology } \\
\text { - Fall 2002 FTIACs }\end{array}$ & $\begin{array}{l}100 \% \\
(\mathrm{n}=4)\end{array}$ & $\begin{array}{l}59.6 \% \\
(\mathrm{n}=52)\end{array}$ & $\begin{array}{l}\mathrm{p}<0.05 \\
\text { (significant) }\end{array}$ \\
\hline
\end{tabular}


There are already three Michigan Tech Enterprises successfully collaborating with high schools to create this type of learning environment: the Aqua Terra Tech Enterprise, Aerospace Enterprise, and FIRST Robotics Enterprise. The success of these relationships is the inspiration to build an official and expanded link between Michigan Tech's Enterprise program and Michigan high schools. The following is a summary of what these three enterprises have been doing with local high schools.

Aqua Terra Tech Enterprise - Aqua Terra Tech, in an attempt to help high schools in Michigan start programs mirroring Michigan Tech's Enterprise Program, has developed the Earth and Hydro-Science Outreach (EH-SO) program. EH-SO (pronounced "A-SO") is collaborating with Cass Technical High School in Detroit, Michigan to make this a reality. This collaboration is intended to help with the conception of a pre-college enterprise program, and to spark students' imaginations into the possibilities that a career in the sciences, more specifically engineering, may hold for them.

The EH-SO group is currently writing and compiling a "project manual" to send to the students of Cass Tech to aid them in their tasks. The project manual will include two primary sections; Enterprise Formation Instructions and Project Instructions. The Enterprise formation instructions will contain ideas and examples on how to form a team, how to hold a meeting, what meeting minutes and an agenda are, etc. These instructions will help the students at Cass Tech develop a working enterprise. The project instructions will describe what is known as a rain garden. A rain garden is an area of the ground engineered to accept the runoff water from roofs, parking lots, etc. This water is funneled into a certain area called a rain garden where many native plants are placed to aid in the recharge of local aquifers, which in turn helps divert a portion of the community's runoff from having to be treated at a wastewater facility. This project manual will act as a "guide" for the students, meaning that there is a lot of room for their own decisions, design, and engineering.

AeroSpace Enterprise - The MTU Aerospace Enterprise began in the fall of 2002 when a group of students began to pursue the dream of designing and building a satellite capable of spaceflight. Since then, the program has had great success with a main point of pride being a third place finish in the University NanoSat 3 competition. Thirteen universities competed with a relatively small budget given from NASA and the Air Force Research Laboratories to design and build a nano-satellite. The MTU Aerospace Enterprise held a strong showing to be named one of three vehicles named flyable or capable of completing its mission.

As part of the NanoSat competition, the enterprise recruited students and faculty from Calumet High School to join them in developing and fabricating a satellite prototype. Teaming up with a high school gave them an edge with NASA in the grant application process as well as allowing high school students a rare opportunity to work on a project such as this. Enterprise faculty advisor, Dr. Brad King, states "The program requires outreach, and the way I decided to involve high school students was to have them participate in the project. I didn't want to do something artificial like a classroom demonstration. The inspiration gained by actually building a spacecraft will surpass anything I could give them in a classroom. Calumet had a great engineering design program, along with state-of-the-art fabrication facilities for industrial arts. Some of the NanoSat parts were actually designed and constructed at the high school." 
FIRST Robotics Enterprise - Since 1999 there has been collaboration between the FIRST Robotics Enterprise, the Copper Country Intermediate School District, and the Houghton High School. The FIRST Robotics Competition is an exciting, multinational competition where teams of professionals and young people worked to solve an engineering design problem in an intense and competitive way.

Most FIRST Teams are partnerships between corporations and high schools, but the Michigan Tech model has college students acting as engineer/mentors to the high school students. This model has proved very beneficial for both groups. The college students get an opportunity to manage a significant project budget, do engineering design and analysis, fabrication, and many other administrative and technical tasks. Meanwhile, the high school students work closely with the college students taking on as much responsibility as they are able. Each year, the organizational culture is a bit different depending on the skill set and ambitions of the two groups. It is always the goal of the FIRST Robotics Enterprise to have the high school students as involved as possible in the process while maintaining a high quality program.

We envision building upon these three successful initiatives to develop a formal Michigan Tech/High School Enterprise Program. By applying the lessons learned by these groups toward the objectives of the Mroz Commission, we believe we can build a significant program that will benefit both college and high school students in a unique way and can then potentially be applied to the elementary and middle school levels as well. A recent Time magazine article ${ }^{1}$ by Claudia Wallis and Sonja Steptoe commented on the typical public school agenda of having the students “...sit in rows, listening to teachers lecture, scribbling notes by hand, reading from textbooks that are out of date by the time they are printed...". The article also commented on the need to have students collaborate, work in groups, and to apply what they have learned to the real world. We couldn't agree more! The program we are proposing represents a paradigm shift in public education. One which we hope will help to transform the learning environment in our public schools and help prepare students for the challenges of the $21^{\text {st }}$ Century global economy.

Moving forward in July of 2006, Michigan Tech brought several high school teachers and administrators, together with MTU faculty and students to begin development of an implementation model for a high school level Enterprise Program.

\section{MTU/CCISD Summer Workshop Background/Description}

In April 2006, high school students and teachers from the local school district attended the Michigan Tech Undergraduate Expo, where undergraduate Enterprise teams showcased the results of their project work completed during the 2005-06 academic year. The teachers were subsequently polled to see if they would be interested in a high school version of the Enterprise Program and the response was positive. Ten local teachers and their administrators were then invited to a two-day summer workshop in July 2006, along with Michigan Tech faculty, students and administrators. The goal of the workshop was to explain the operation and objectives of Michigan Tech's Enterprise Program and then to develop a curricular framework for a high school version of the program together with initial plans for implementation. 
At the conclusion of the workshop, these teachers went back to their home districts to present the idea to students and administrators and again the feedback was generally positive. Administrators were very supportive of the concept provided the associated costs wouldn't burden their already strained operating budgets. A follow-up one day workshop was held in October at which time details of the program structure, curriculum, and associated funding needs were developed. A timeline of actions to be completed in order to pilot a high school Enterprise Program in the fall of 2007 was also developed. At this time, implementation actions continue and Michigan Tech is in the process of writing proposals to seek funding for the program so that it can be piloted starting in fall 2007 with three local and two distant enterprise teams.

\section{Proposed High School Enterprise Model}

In this model, high school teachers will be paid to "coach" student teams on how to plan and complete a project. Teams will meet after school and some weekends (as athletic teams currently do) to work on projects, and will use the existing Michigan Tech Enterprise Program, students, and faculty advisors as resources. Industry may also provide resources such as people, materials, and facilities depending on the situation of each enterprise group. A Michigan Tech coordinator will act as a liaison between high school enterprises, the University, and industry.

Each participating high school teacher will coach a group of students working on one or multiple projects in a focused area. The program will be open to all high school students in grades 9-12, with the expectation that students participate over several years. The groups will meet 2-3 times per week for 2-3 hours each. During this time, they will:

- Develop an idea for a project (e.g., students brainstorm, teacher presents alternatives, Michigan Tech provides suggestions or the group may choose to tackle one component of a complex project.)

- Define the problem or project (scope, outcomes) and determine overview/timetable. Examine personnel and equipment issues, develop proposed budget.

- Present proposal to committee made up of representatives from the Michigan Tech Enterprise SmartZone, industry and Michigan Tech by mid- to late-September for review and budget authorization.

- Work on project, utilizing preexisting ties to Michigan Tech and industry. (Michigan Tech will develop cadre of mentors for this purpose).

- Present project work at Michigan Tech Undergraduate Expo in April

The project may be completed in one year, or it may become a multi-year undertaking. It will be expected that high school students be in the enterprise for two or three years. Ideally they would join as sophomores or juniors and take on increasing responsibility or load each successive year.

After meeting with the high school teachers in July 2006, a plan was developed which calls for three local and two distant enterprises to be started. The current relationships involving the Robotics, Aerospace, and Aqua Terra Tech Enterprises will continue, but will be more highly structured to ensure the desired outcomes of this initiative. In addition to these a new high school enterprise will be started involving local area high schools with a focus on sustainable resource use. 
The proposed name of this new enterprise is the Sustainable Resources Enterprise, the idea for which came from the high school teachers who identified a desire in their students to work in this field. The Copper Country economy relies heavily on both forest products and tourism. Therefore there is a need for sound, sustainable forest practices that do not harm the natural beauty that supports the tourist industry. There are boundless opportunities for projects in these areas including many identified by teachers. A few project ideas generated by teachers are; designing efficient forest harvesting equipment and techniques, finding new uses for forest products, developing wind powered electrical generation, using forest resources to produce biofuel, and setting up environmental monitoring stations.

Another result of the July teacher's workshop was a list of student outcomes for the program. These were developed to align with the needs identified by the Cherry Commission report as well as the new Michigan Merit Core Curriculum. The fact that high school teachers developed these is very important because the outcomes are much more likely to be enthusiastically embraced than if they were "handed down" from above. The draft list of student outcomes is presented below, but this list is going to be further refined in summer 2007 before the pilot is implemented.

Student Outcomes - As a result of their participation in the enterprise program, high school students will

- be measurably prepared to enroll and succeed at a college or university.

- have the confidence and ability to choose fields that meld entrepreneurship, innovation and business with engineering, science \& technology skills.

- define, plan, and complete projects that will ultimately result in a product, process or system useful to a business, an industry, the school, and their community.

- develop entrepreneurial skills through active, discovery-based learning and involvement in projects similar to the successful models in the Michigan Tech Enterprise Program.

- be intellectually engaged in the enterprise components, especially those individuals or members of groups who are not traditionally academically successful.

- be measurably interested in enrolling in higher level course work that will enhance their new interests.

Along with student outcomes, there is also a need for program outcomes. These were also drafted and are presented below. They are directly related to the Cherry Commission report and the Michigan Merit Core Curriculum.

Program Outcomes - The program is intended to drive the following outcomes:

- more students will enroll in college who ordinarily would not

- students will seek careers in STEM fields

- students will work in the state of Michigan in a STEM related career

- the program will be replicated throughout the state

- the program will become part of the state curriculum

Measurement of these outcomes will be the core of the assessment piece for the program, which is still being developed at Michigan Tech. 
Program Dissemination and Growth - An important facet of the project is that it be replicable to schools in a variety of settings; urban, suburban and rural. To this end, the pilot program calls for projects to be implemented concurrently in Upper Peninsula schools (rural) as well as schools in the metro Detroit and surrounding area (urban and suburban). Beyond that, the model will be made available across state lines, with K-12 districts partnering with a local University, or with MTU via distance-communication. Initial plans call for four new Enterprises and locations to be added in 2008 and 2009. How the program grows will ultimately be a function of program assessment and funding. Parallel efforts will include curricula design incorporating the new Michigan Merit Core Curriculum.

\section{Integrating an Enterprise Model into the High School Curriculum}

The pilot will begin as an extracurricular program, however for this initiative to be successful in the long term it needs to help students meet the state graduation requirements developed in response to the Cherry Commission. The new Michigan Merit Core Curriculum establishes a rigorous set of graduation requirements that are among the best in the nation. The requirements were created to prepare students with the skills and knowledge needed to meet the demands of the 21st Century global economy.

The Merit Core Curriculum consists of a total of 18 credits in the areas of English language arts, science, mathematics, social studies, visual and performing arts, health and physical education, and world languages that all Michigan students must complete in order to graduate. Specific course work is outlined for each of the content areas that students must complete. Course content expectations determine the amount of content to be covered for one credit in a particular course. For more information about the Michigan Merit Core Curriculum, visit www.michigan.gov/highschool.

All students must complete four credits of mathematics and three credits of science. The four credits of mathematics consist of Algebra 1, Geometry and Algebra 2 and an additional credit. Students must also be enrolled in a mathematics course during their senior year. The fourth credit could be taken during their senior year after completion of Algebra 1, Geometry and Algebra 2. There are no specifications given by the Michigan Department of Education (MDE) or by legislation as to what content the additional mathematics course should contain. The content of this course is left up to the individual school districts. Courses such as those proposed with the Enterprise Program could be used to fill the fourth mathematics credit. The three credits of science consist of Biology, Chemistry or Physics, and one additional science credit that addresses the basic concepts of earth and physical science.

The High School Enterprise Model provides a vehicle for districts to meet the requirements of the Merit Core Curriculum and provide relevant learning experiences for students. The content of enterprise model engages students in real world applications of the core mathematics and science concepts by solving challenging engineering problems found in industry. The complexity of projects of a chosen enterprise will determine the prerequisite math and science knowledge that the students will need to be successful. 
There are two possible options for school districts to integrate the Enterprise Program into their curriculum. One option is to tailor the Enterprise Program to meet the fourth mathematics credit requirement. Another option is to offer the Enterprise Program as a science course. Each school district will need to decide how to best integrate the Enterprise Program into their curriculum to meet the needs of their students and the graduation requirements of the state. The benefit of meeting these needs with the Enterprise Model, as opposed to traditional classes, is students are solving in real world problems using math and science concepts. Additionally, students will be motivated to pursue post secondary education leading to careers in STEM related fields.

\section{Implementation Plans/Program Sustainability}

Establishing this model as a part of the state curriculum is a critical factor in sustaining the program. Program planning will continue through the spring and summer of 2007 with another in-service workshop scheduled for summer 2007 for the teachers involved in the pilot program. Pilot implementation of this project will start in the fall of 2007 with the establishment of three Enterprises in local high schools and two high schools out of the region. Parallel efforts will include curricula design incorporating the new Michigan Merit Core Curriculum. Initial plans call for an additional four new Enterprises and locations to be added in 2008 and 2009. Successful program outcomes assessment and funding will drive future growth of the program. Current funding sources that are available or being pursued include current sponsors of the Michigan Tech Enterprise Program, the State of Michigan, other corporations, foundations and private donors.

\section{Summary and Conclusions}

In conclusion, the success of Michigan Tech Undergraduate Enterprise Program, together with the need for innovative learning environments in the K-12 education system, inspired a group of university and high school faculty and administrators to collaborate on the development of an enterprise-like model for implementation at the high-school level. While still in the early stages of planning and development, we are encouraged by the ability of the Michigan Tech Enterprise Program to generate a higher level of enthusiasm in the STEM fields among participating undergraduate students and anticipate a comparable level of success when extending this program to the high schools. Long term, we hope this pilot will result in a high school educational model that can be readily extended throughout the region and state, and eventually drive a true paradigm shift in public education across the country.

\section{Bibliography}

1 "How to Bring Our Schools Out of the $20^{\text {th }}$ Century", Time, December 18, 2006, pp. 51-56. Claudia Wallis and Sonja Steptoe. 